\title{
Pedagogical Tools in the 21st Century
}

\author{
M. Aherrahrou, A. Makhoukh, J. Koubali \\ English Department, Moulay Ismail University, School of Arts and Humanities Meknes, \\ Morocco \\ Meryem_ah@yahoo.com
}

\begin{abstract}
Neuro-Linguistic Programming has attracted considerable attention in many different areas of life mainly in education. In this context, the major aim of this paper was to explore the implications and effect of Neuro Linguistic Programming (NLP) techniques in English language Teaching and Learning in the Moroccan context. Qualitative and Quantitative methods are used. In this study, we included 2 teachers with and without NLP experience as well as 2 groups including 43 students. Our results stated that after implementing NLP techniques in the classroom, teacher and learners participate together to create a positive atmosphere, increase productivity, motivate themselves to achieve excellence and reach their desired outcome not only inside the classroom but also in their personal life.
\end{abstract}

Keywords: Neuro Linguistic Programming, Learning, teaching, classroom

\section{Introduction}

In the new millennium, inspite of the great effort made to improve the quality of education. There remain a few challenges and constraints related to teaching and learning. However, Neuro-Linguistic Programming (NLP) has been proposed by many scholars Yero (2002); Millrood (2004); Tosey and Mathaison (2010) as a solution to problems encounter in teaching Tosey and Mathaison (2003). It was first developed in the early seventies from the collaboration of J. Grinder and R. Bandler. Those authors have created set of patterns, techniques and strategies that other people can use to achieve excellence Revell and Norman (1997). In the past few years, NLP has attracted considerable attention in many areas of life (O’Connor and Seymour ( 1990); Tosey, Mathaison and Michelli ( 2005) mainly in education Tosey and Mathaison (2008); Caret, Churches, Hutchinson, Jones, \& Tosey (2009); 
Pishghadam, Shapoori, and Shayestech (2011); Allan, Bourne, Bouch, Churches, Dennison, Evans, Fowler, Jeffers, Prior, and Rhodes (2012). In fact, a number of empirical research examined and explored the effect of NLP in English language teaching in other countries but not in Morocco. According to NLP research Database, no study has been conducted in the context of Morocco yet regarding NLP in Education; more specifically, in English language teaching.

Tosey and Mathaison (2003) explained how NLP is being applied widely if often informally in UK education" p. 371. Thus, Carey et al., (2009) explored the implications of the use of Neuro Linguistic Programming by teachers, and how it affected the students and classroom dynamics positively. In an other attempt, Pishghadam, Shapoori, and Shayesteh (2011) explored the application of NLP principles and its relationship with teacher success, gender, teaching experience and degree in the process of English language teaching and learning in both formal and informal context in Iran; concluding a significant relationship between NLP and teacher success. Similarly, Millrood (2004) conducted three workshops for 16 English teachers of at least five years of teaching experience to enhance teachers' awareness of NLP in their classroom discourse, in context of Russia. The workshop provides evidence that teacher discourse can be considered as a tool, programming success or failure in learners by creating or ruining teacher learner congruence through a set of NLP techniques.

In another similar view, Kudliskis and Burden (2009) explored whether NLP can help enhance exam success. They concluded that NLP could act as a helpful stimulus for communication between teachers and learners about the learning process as cited in Targutay (2010). Additionally, in his article, Cũpane (2004) analyzed the basic principles, presuppositions and techniques of NLP that may help enhance the acquisition of English as a foreign language in Latvia. The obtained results reveal that the NLP techniques implemented enhanced students' motivation and success. In their recent articles, Vieira and Gaspar (2012) explored how NLP can contribute to improving teachers' effectiveness through professional training. They concluded that "training teachers in NLP techniques and strategies can be a major contribute" p. 16. In their article, Carey, Churches, Hutchinson, Jones, \& Tosey (2010) reviewed the content of 111 studies/ articles about NLP applications in schools. The review proved that the majority of published work was found to be supportive of the use of NLP in schools and education.

So, the major purpose of this article was to explore the implication and effect of certain NLP techniques in the process of English language teaching and learning in a semi public institution in Morocco so as to confirm or disconfirm the findings of other researchers. 
To be more exact, in this study we attempted to test the following Hypothesis:

H: Teachers of English with NLP training are more successful than those who used to apply old methods in teaching regardless of their experience and produce productive students heedless of their level of proficiency and major.

\section{Material and Methods}

\section{Techniques and strategies}

As mentioned earlier, there are many techniques and strategies, which can help teachers to improve the teaching- learning environment in the classroom but in this work we will limit ourselves to:

\section{Representational system}

Are the systems that we use to internally code and store the data that we take in through our five senses Vaknin (2008) All human beings are unique and each of us will tend to have a preferred representational system that we use to organize our experience and to construct our internal maps of reality. Some of us will be mainly visual, others will have a preferred representational of auditory, however others still find that their preferred representational system is kinaesthetic. In education, Hamilton (2003) suggested that teachers should first find out their own as well as their students' preferred learning style so that, the lessons is delivered by addressing the needs of all Rosenberg (1986); Revell and Norman (1999).

\section{Modelling}

Modelling is at the very heart of NLP. It is the process of extracting and replicating the language structure and behaviour of an excellent individual in any task or activity. Revell and Norman (1999) explained how “ Modelling requires careful observation strategies so as to notice what the person being modelled does, and try to imagine what it is like to be in their " skin" as cited in Targutay (2010) p, 107. In this context, Tosey (2008) explored whether NLP modelling works in essay writing. He offered a seven steps modelling framework for essay writing. The findings reveal that the framework was effective in developing students essay writing skills. 


\section{Metaphor}

As O'Connor and Seymour (1990) put it "the word metaphor is used in NLP in a general way to cover any story or figure of speech implying a comparison. So that, "to shape the way we think about the world, and therefore, the way we behave in relation to it" Revell and Norman (1999) p. 72. In his dissertation, Targutay (2010) explained how this stories and analogies can enable students to make more sense of what they learn" p. 23

\section{Building Rapport}

According to Vaknin (2008) Rapport is one of the first areas that NLP became fascinated with as it developed. Very simply, Ellerton (n.d) defined Rapport as "as establishing an environment of trust, understanding, respect, and safety; which gives a person the freedom to fully express their ideas and concerns and to know that they will be respected by the other person" p. Childers. J (1985) showed how "NLP help teachers establish rapport and effective communication with learners" $p$.

\section{Well defined outcome}

Goal setting has become important for achieving success in most areas of life. In O'Connor' (2001) own words 'an outcome is what you want_a desired state, something you don't have in your present state' p .11 According to Denis Watley “ the reason most people never reach their goals is that they don't define them, or even seriously consider them as believable or achievable. In his view, winners can tell you where they are going, what they plan to do along the way and who will be sharing the adventure with them" as cited in Vaknin (2008) p. 43.

\section{Statistical analysis}

For statistical analyses we used the unpaired t-test. Data are presented as mean \pm standard error of the mean (SEM) and P-values of $<0.05$ were considered as statistically significant $(* \mathrm{p}<0.05, * * \mathrm{p}<0.01$ and $* * * \mathrm{p}<0.001)$

\section{Case Study : NLP application}

In order to investigate the implication and effect of certain NLP techniques in the process of English language teaching in a semi public institution in Morocco, the study reported here used mixed methods design, which aimed to overcome the weakness or intrinsic biases and 
the problems that come from single method and confirm the finding from multiple data source (Creswell 2003).

\section{Participants}

The participants of this study include two teachers and their respective two groups.

Group A: In this group we have a male teacher who had over nine years of teaching experience and has a full time job. He has a bachelor degree but never attended a seminar or workshop in NLP. His age is over 40 years old. In his group, there were about 24 students. Their ages were between 22 and 28 years old. They belong to different social class, as will as different regions of Morocco; namely Titouan, Elhajb, Meknes, Errachidia and Azrou and Ifrane. In this group there were 13 females and 11 males. Their level of proficiency was very advance. Most of them are Baccalaureate, D.E.U.G and B.A holders representing different disciplines.

Group B: This group has a female teacher who had four years experience and work part time job. She has a master degree. She is well informed about certain NLP strategies. Her age is under 30 years old. She used to teach different levels either in private or public institution. She has never benefited from any pedagogical training before. In her group there were 19 students 4 males and 15 females aged between 21 and 26 years old. Most of them belong to the lower and middle classes. They come from different regions of Morocco, namely, Agadir, Titouan, Elhajb, Meknes, Errachidia and Azrou. Their level of proficiency was very low. Thus most of them have less than baccalaureate.

\section{Instruments}

In order to measure the effect and implication of certain NLP strategies in the Moroccan context, mixed method are used.

In term of quantitative method: two questionnaires were used; one was designed for the purpose of measuring teachers' demographic information and familiarity with NLP in the classroom and the other one was designed to determine the learning styles of the group B, whose teacher has benefited from NLP training.

The first questionnaire comprises 24 items ranging from (5) "strongly agree" to (1) strongly disagree" requiring 10 minutes to make their choices. It consists of two sections. The first section captured respondents' demographic information. It included questions about the respondents' age, gender, level of education, years of experience and familiarity with NLP. The second section comprised a query about the concept of NLP including questions about 
representational system, building rapport, metaphor, modelling and finally well-defined outcome.

While the second questionnaire comprises 12 items ranging from (4) always to (1) never allowing ten minutes for them to make their choices to determine how each learning style is used by the learner. Each item contains three multiple-choice questions related to the visual, auditory and kinaesthetic fields.

In term of qualitative method: classroom observation was carried out over one month at an educational institution in Morocco. The major aim of this classroom observation is to explore teachers' success in application of certain NLP techniques in the classroom and examine their effect in term of students' achievement.

\section{Procedures}

This study was undertaken in a semi public institution in Morocco, near the end of the second term. Seven teachers from the aforementioned institution were asked to fill the NLP questionnaire. Two teachers refuse to fill the questionnaire while the two others accepted our request; three of those teachers did not give back our paper. During our first week of classroom observation we have asked students of the group B to fill out the questionnaire about their preferred learning styles.

\section{Results and discussion}

To determine the effect of certain NLP techniques in English language teaching and learning in one educational institution in Morocco, two questionnaires, classroom observation and students' marks of both teachers are used

\section{Questionnaires analysis}

In this work two questionnaires are conducted:

The first one helped us to realize what sort of learners we had in group B with NLP training and application 

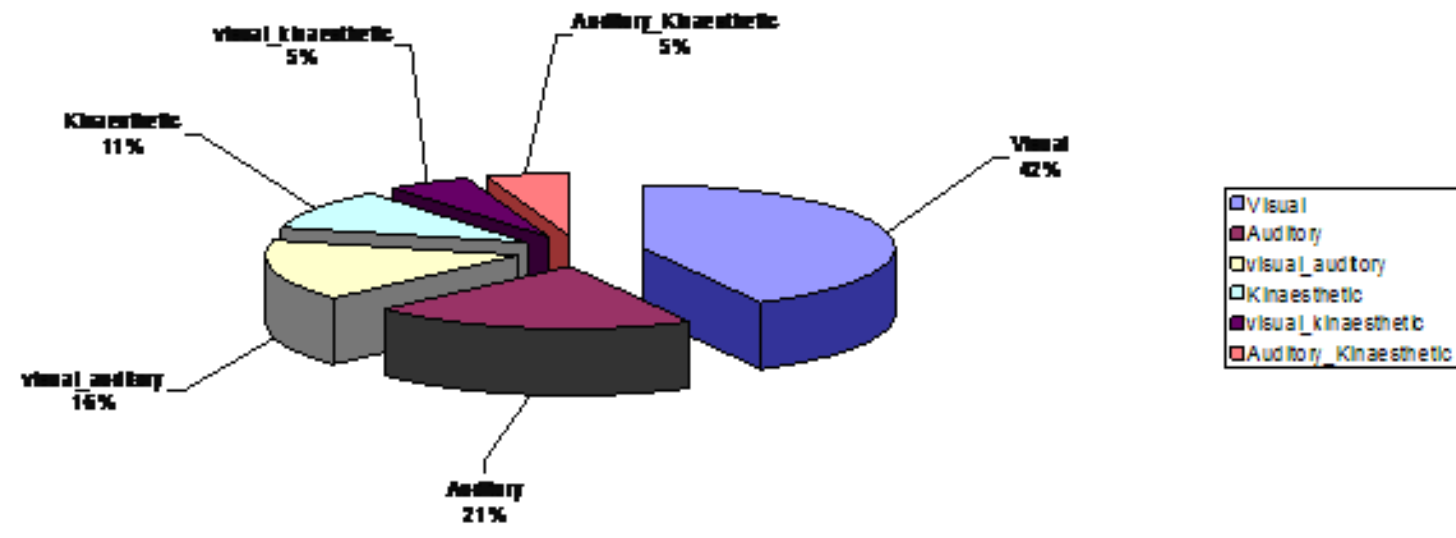

Figure 1: Illustration of the percentage of representation systems of group B

We have evaluated it as follows: 8 of the students were Visual, 6 of the students were Auditory, three of them were Visual- Auditory, 2 of them were kinaesthetic, 1 of them was Visual-Kinaesthetic and finally 1 of them was Auditory-Kinaesthetic.
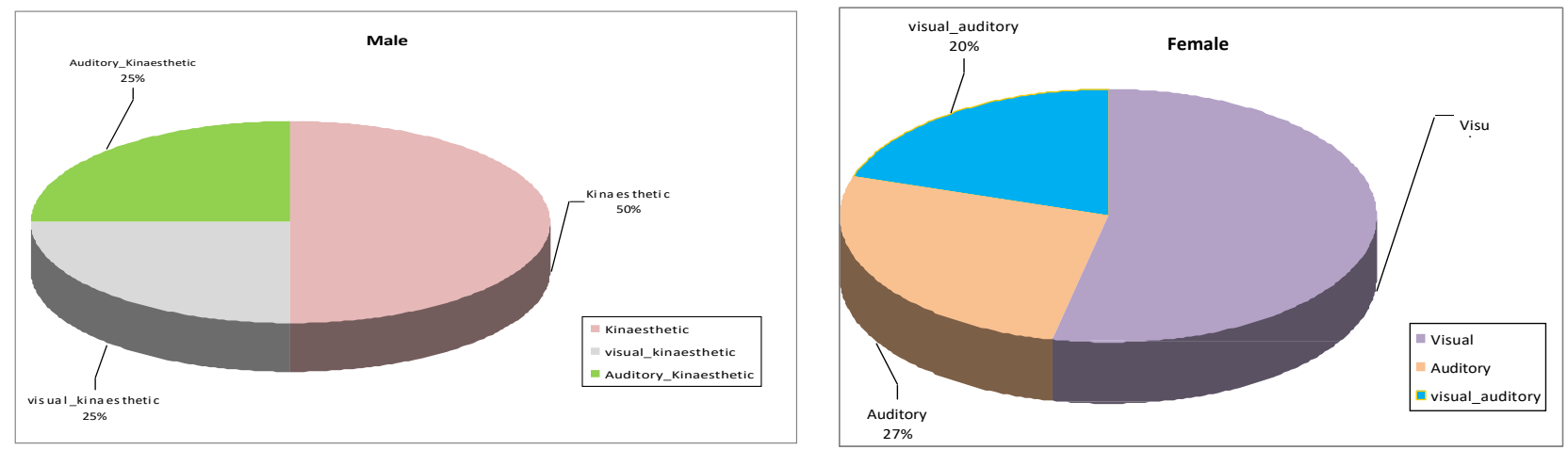

Figure 2: Male and female students and their representational system

Furthermore, learning styles seems to be dependent on gender. In this group, female students are visual, auditory learners. However, male students have completely different type of learning style and tend to adopt the kinaesthetic learning style in their process of acquiring the language skills.

The second one was used to measure teachers' demographic information and familiarity with NLP. The following finding can be stated: only one female teacher who was well informed about NLP techniques because she has already benefited from training in NLP while the other teacher was not aware of it.

\section{Classroom observation analysis}

The major aim of classroom observation, carried over one month at a semi public institution in Morocco, is to investigate and examine teachers' success in applying NLP strategies in 
their classroom and how it affects the productivity of their students. However, the analysis of the obtained results showed that the female teacher with NLP training is more successful in term of implementing certain NLP patterns such as, modelling, well defined outcome, building rapport with her students, using different representational systems while explaining the course and metaphor as to make the course more memorable for her students. All of which made a difference in her classroom and increased the productivity of group B students.

Unlike the male teacher with no NLP training tends to be less successful in his class because of the missing of NLP techniques. As a result of this students are not interested to his course and what make it worse is that an atmosphere of abuse, bullying exists in the classroom. Which really affect the productivity of both teacher and students of group A. It can be concluded from classroom observation that NLP has potentiality to make positive change in Education' as cited in Pishghadam et all (2011) p. 3

\section{Students' mark analysis}

To check the validity of the obtained results from both questionnaires and classroom observation, we have asked the administration the evaluation of both groups at that educational institution in Morocco. And then we tried to compare the marks of students before and after implementing certain NLP techniques.

The first figure reflects the marks of the group A whose teacher given no NLP training.

\section{Group A with no NLP}

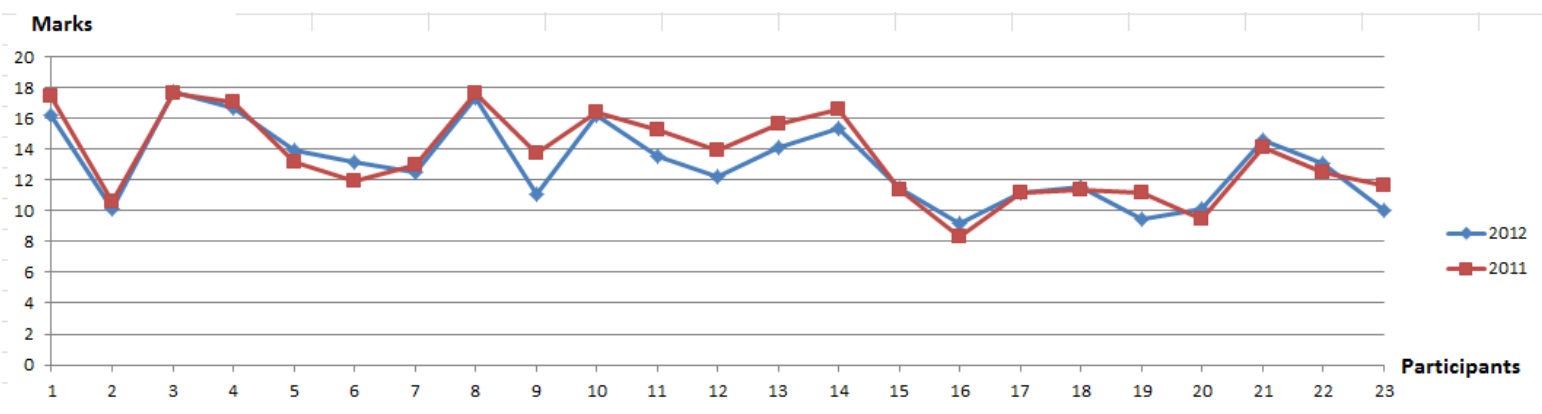

Figure 3: Students' mark of group A with no NLP application in 2011 and 2012

The second figure reflects students' mark before and after the application of NLP techniques.

\section{Group B with NLP}




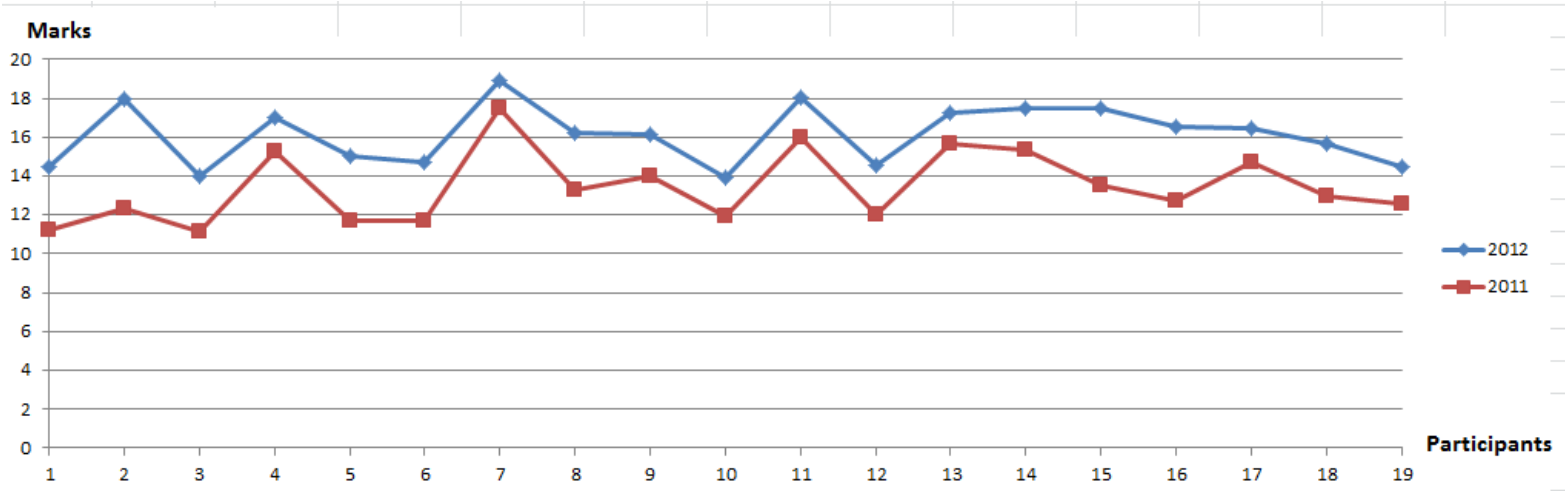

Figure 4: Students' mark of group B without NLP in 2011 and with NLP in 2012

The following diagram shows us in more detail the kind of correlation between the two variables within the two mentioned groups.
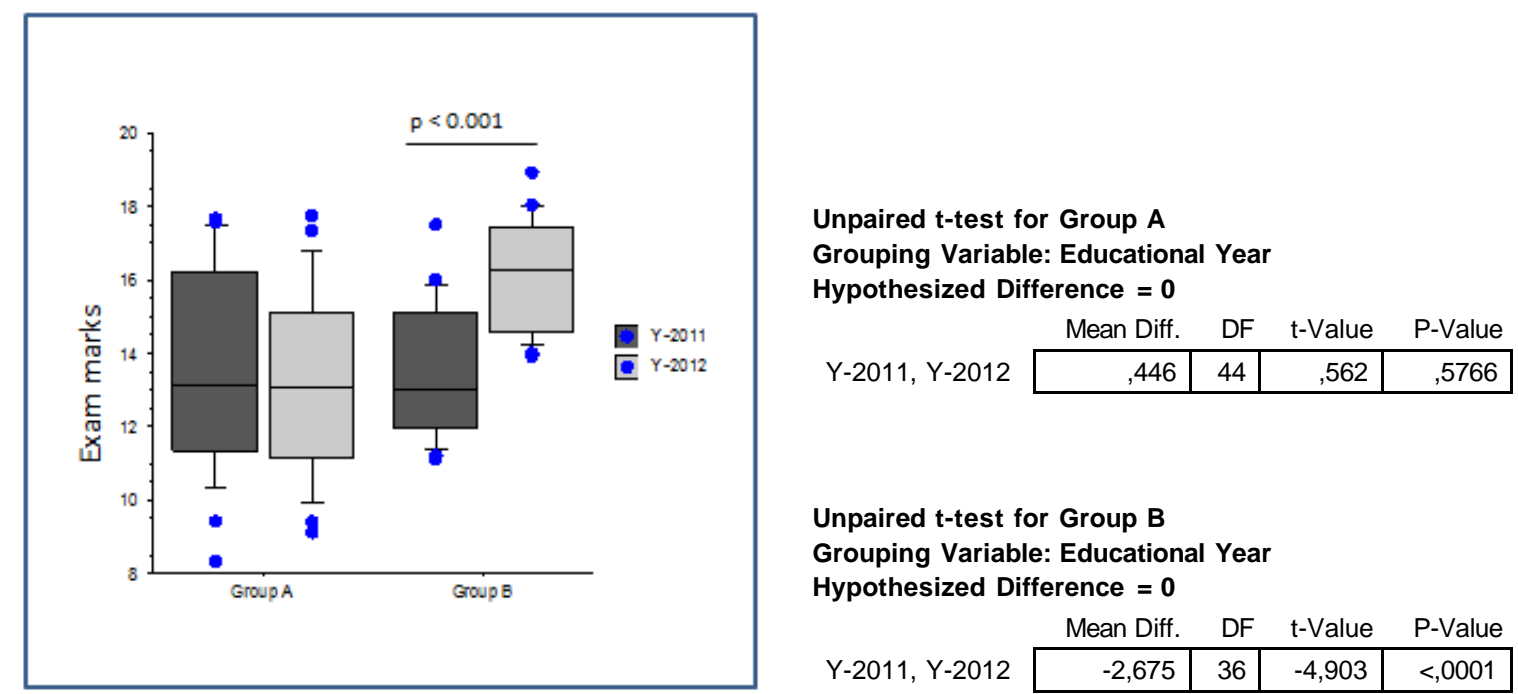

Figure 5: Box plots representation of the marks of the students in groups A and B in 2011 and 2012.

Group A, as it is shown from this diagram that there is no significant correlation between the two variables because $\mathrm{P}=5766$. Therefore, $\mathrm{P}>0$ demonstrated that there a positive relationship between the two variables as the exam marks of group A students remain nearly the same in 2011 and 2012 (mean difference $\mathrm{MD}=0.446$ ) even most of them are B.A and D.E.U.G holders.

In contrast, with group ' $\mathrm{B}$ ' which shows that there is a significant correlation $(\mathrm{p}<0.001)$ between the two variables (NLP and exam marks) since the exam marks of group B students' had significantly improved in 2012 (mean difference $M D=-2,675$ ) even they have less than baccalaureate and most of them were specialised in literature.

Taken together, the group B benefit from the application of NLP techniques demonstrated an improvement in marks in 2012 compared to 2011. However, the results of group 'A' students 
slightly decreased over the period of 2012 because of the missing NLP technique application by their teachers in the classroom. These showed that there is a perfect correlation between the two variables (NLP and students achievement) so that our hypothesis concerning the effect of NLP techniques at that educational institution in Morocco is perfectly correct which demonstrate its effectiveness within Moroccan education. More applications in other institutions are needed.

\section{Conclusion}

It can be concluded that the obtained results from questionnaires, classroom observation and students' mark have proven the effectiveness of NLP patterns in one educational institution in Morocco. The findings have proven a highly significant relationship between NLP, teacher success and students achievements. As we have stated above, the teacher using more NLP techniques is more successful than the one who do not employ NLP techniques. All in all NLP provides the tools and strategies with which educational excellence can be achieved and maintained Millrood (2004).

In this study, we tried to investigate the effect of certain NLP technique in one educational institution in Morocco using small participants (two teachers and two groups including 43 students) because the number of teachers who are trained in NLP is very limited in if not possible in Morocco. So that more training on the part of teachers are needed as to confirm or disconfirm our findings. Further research needs to be conducted to test the validity of other techniques. 


\section{References}

Allan,F., Bourne, J., Bouch, D., Churches, R., Dennison, J., Evans, J., Fowler, J., Jeffers, A., Prior, E. and Rhodes, L. (2012). Training in influencing skills from neuro-linguistic programming ( modelled from hypnosis and family therapy), in combination with innovative maths pedagogy, raises maths attainment in adult numeracy learners. Paper presented at the third international NLP Research conference. Hertfordshire University- $6^{\text {th }}$ and $7^{\text {th }}$ july 2012

Bandler, R., and Grinder, j.( 1975). The structure of Magic, Volume I: A Book about Language and Therapy. Palo Alto CA: Science \& Behaviour Books.

Bandler, R. and Grinder, j. (1976). The structure of Magic, Volume II. Palo Alto CA: Science \& Behaviour Books.

Carey, J.,Churches, R., Hutchinson, G., Jones, J., Tosey, P. ( 2009) Neuro- Linguistic Programming and learning: teacher case studies on the impact of NLP in education, Reading: CFBT Education Trust.

Childers Jr., J. H ( 1985). Neuro- Linguistic Programming: Enhancing teacher_student communication. Journal of Humanistic Education 24( 1), 32-39

Churches, R. and West-Burnham, J. (2009) Leading learning through relationships: the implication of Neuro-Linguistic Programming for personalisation and the Children's Agenda in England, in P. Tosey, ( ed), Current research in NLP, vol 1: proceedings of the first international NLP research conference, University of Surrey, 5 july 2008, south Mimms, Hertfordshire: ANLP international CIC, pp.126-136

Cupane, G. (2004). Use of the elements of Neuro- Linguistic Programming in the enhancement of the acquisition of the English. Pedago ija, 71

O'Connor, J., and Seymour, J.( 1990). Introducing Neuro- Linguistic Programming: Psychological Skills For Understanding And Influencing People. Great Britain: England.

O'Connor, J. (2001). The NLP Workbook : A practical Guide to Achieving the results you Want. London: Element

Hamilton, R. ( 2003). The NLP spelling strategy. Humanizing Language Teaching. 5( 1)

Millrood, R. ( 2004). The role of NLP in teachers' classroom discourse. ELT journal. Vol. 58(1) January 2004. Oxford university press

Kudliskis, V., \& Burden, R.(2009). Applying ' what works' in psychology to enhancing examination success in schools: The potential contribution of NLP. Thinking Skills and Creativity 4( 3), 170-177

Pishgham, R., Shapoori, M., and Shayesteh, S.,( 2011). NLP and its relationship with teacher success, gender, teaching experience, and degree: A comparative study". World journal of English language, 1(2) 2-8

Revell, J. and Norman, S. (1997). In your hands: NLP in ELT. London: Safire Press. 
Revell, J. and Norman, S. (1999). Handing over- NLP based Activities for language learning. London: safire Press.

Rosenberg. M. (1986). The how of thinking. Philadelphia: Temple University Press

Targutay, M. ( 2010). The role of Neuro Linguistic Programming in English Language Teaching: NLP- trained Language Teaching Practitioners' Perceptions About NLP Strategies And Techniques used in Classes. Dissertation thesis

Tosey, P. ( 2008). ' it's a living thing': A Neuro- Linguistic Programming perspective on essay Writing. Humanising Language Teaching, 10(5).

Tosey, P., \& Mathison, J. ( 2003). Neuro- Linguistic Programming: its potential for learning and teaching in formal education. Paper presented at the European Conference on Educational Research, University of Hamburg, 17-20 September 2003.

Tosey, P., Mathison, J., \& Michili, D. (2005). Mapping transformative learning: the potential of neuro-linguistic programming. Journal of Transformative Education, 3(2), 140-167

Tosey, P., \& Mathison, J., ( 2010). Neuro- Linguistic Programming As An Innovation in Education And Teaching. International,47(3), 317-326

Yero, J. L. ( 2001). NLP and Education: A shift of focus. Anchor Point Magazine, 15, 9.

Yero, J.L. ( 2002). Teaching in mind: how teacher thinking shape education. Hamilton, MT: Mind Flight Publishing.

Vaknin, sh. (2008). The big book of NLP techniques: 200+ patterns Methods \& strategies of Neuro Linguistic Programming. ISBN

Vieira, C.R. and Gaspar, M.F. (2012). Plenatitude: teacher education for effectiveness and well- being with neuro-linguistic programming, $4^{\text {th }}$ Association for Teacher Education in Europe Winter Conference, Coimbra, $4^{\text {th }}$ September 